Article

\title{
Experiences in Transdisciplinary Education for the Sustainable Development of the Built Environment, the ISAlab Workshop
}

\author{
Javier Orozco-Messana * ${ }^{\mathbb{D}}$, Elena de la Poza-Plaza $\mathbb{D}^{\mathbb{D}}$ and Raimon Calabuig-Moreno \\ Universitat Politecnica de Valencia, 46022 Valencia, Spain; elpopla@esp.upv.es (E.d.1.P.-P.); \\ raicamo@arqt.upv.es (R.C.-M.) \\ * Correspondence: jaormes@cst.upv.es;
}

Received: 17 December 2019; Accepted: 5 February 2020; Published: 5 February 2020

check for updates

\begin{abstract}
There is a growing recognition and acceptance that society needs to develop new pathways to achieve a more sustainable future. Our current model of development poses significant challenges when it comes to achieving a more just society based on respect for nature and human rights, and demands a sustainable economy supported by a new circular model supporting the UN sustainable development goals. Higher Education Institutions (HEIs) accordingly have developed Master programs that are responsible for providing fundamental services in the joint effort towards sustainability. Meanwhile, leading Universities around the world have developed other very relevant programs. The open and unstructured challenge of sustainability poses an obstacle to existing academic structures. Specifically, the built environment is one of the leading contributors to challenges addressed in the programs such as: Anthropogenic climate change, resource depletion, waste generation and pollution, poverty, and inequity. The Interdisciplinary Sustainable Architecture lab (ISAlab) explores these issues as part of a multidisciplinary approach involving the collaboration of leading Universities from different areas on the world through an innovative initiative. This paper explores the experiences of the ISAlab workshop, which has been taking place yearly in Valencia since 2017. The workshop draws together students from a range of disciplines from across engineering and science, law and the social sciences and from a range of countries and backgrounds, including North and South America, Europe, and Asia. Its purpose is to facilitate a rich co-creative learning environment led by (engineering) academic faculties from across Europe (Spain, the UK, France, Germany, Netherlands and Ireland) as well as North America (the US and Canada), as well as local experts who helped provide participants with appropriate context and guidance. The objective is educating future engineers that are capable of finding robust ways to implement sustainability at a practical level on the built environment, taking account of the multidisciplinary perspective and with the incentive of solving real-life problems.
\end{abstract}

Keywords: sustainability education; transdisciplinary education; multidisciplinary education; project based learning

\section{Introduction and Background}

There is an urgent need to develop an awareness among our society about the impact of the UN sustainability goals while bearing in mind all stakeholder groups and a proper recognition of context, as well as the need to collaborate with specialists from other disciplines and professional groups. Only through a team multidisciplinary approach can a proper and successful implementation of sustainable solutions for cities be achieved [1].

By working together, students can develop a plural approach to the desired sustainability of the built environment, expediting the evolution of curriculum development that addresses this context. 
This article presents a project based approach which tries to facilitate the solution seeking process for Urban Sustainability problems. The detailed figures supporting the relevance of this approach are presented in point 3.1, but the following reflection helps in understanding the purpose of the research.

A necessary constraint of the workshop involved the fact that faculty came from several geographic locations, and thus had an incomplete understanding of the local project descriptions in advance, while the students had even less of an understand. In addition, the six faculty members did not have a clear idea of the workshop structure or format for the week ahead, except for having produced a bespoke presentation based on their own backgrounds and expertise. Indeed, the faculty team were only licensed to essentially develop a five-day workshop plan from an outline concept. Nevertheless (or perhaps because of these contextual circumstances), the resultant contingency method was successfully developed by a highly motivated group of faculty, students, and local experts.

The workshop became a highly creative and productive week of co-created learning opportunities and ultimately inspired emergent outcomes at a number of levels. From faculty developing and improving on workshop structures and deliveries collaboratively and 'just in time', to students who initially struggled with concepts and roles, the week culminated in the formulation and presentation of a series of socially sensitive and comprehensively outlined development plans. Like a piece of harmoniously improvised jazz, this was a collective journey laced with creativity, improvisation, and inspiration, which surpassed even our most ambitious goals.

All sustainability problems are multidisciplinary by nature, making them difficult to solve efficiently. This paper describes the process and provides reflections (from both faculty and students) through a number of strands which permeated the workshop. It also speculates on the wider learnings gained from this exercise in Problem Based Learning (PBL), which both facilitated and required innovation, reflection, connection and improvisation amid an ethos and setting a final aim on open transdisciplinarity. The actual interaction of the students, according to Pohl et al. [2], developed around a multidisciplinary problem with interdisciplinary interactions of students and faculty coordinators, aiming for (but not developing full) transdisciplinary conclusions, when related stakeholders participated in the process.

The faculty involved teamed up with Graduate students from a range of disciplines, mainly engineering and architecture related programs (in Engineering for Sustainable Development, Chemical Engineering, Energy, Built Environment, Architecture, and Green Infrastructure) but also from Law. Diversity was further enhanced by the fact that students had various cultural and linguistic backgrounds ranging from across Europe, North and South America, and Asia. Local experts were at hand too from the Valencia region, who helped guide and advise students (some of whom were studying locally at UPV) on the respective projects covered.

The week culminated in student groups presenting their respective proposals concerning a sustainability informed plan for the development of a designated site or area in the Valencian Community, which had been outlined to the groups at the start of the week. The work of the student groups was also underpinned by a series of lectures, given by both faculty and by invited experts, which were aimed at helping to contextualize, inform, and stimulate the students in their work.

The projects outlined to students were identified in advance by the workshop host, who had also assembled a team of local experts who could be used as consultants by the students throughout the week. Obviously, all were based on the different flavours of sustainability challenges related to the built environment and the common link was that they were based on real projects that were under development. The task of the project teams was to see how these could be sensitively developed as an amenity, perhaps for cultural or educational purposes, within an overall 'sustainability' ethos, while considering a mix of environmental, social, economic, and technical dimensions.

Essentially, the projects encapsulated the essence of the kind of challenges we wish to prepare engineers for. This is because they are current, real life, open ended problems with no obvious solutions, requiring multi-actor engagement and interdisciplinary and transdisciplinary approaches, while reflecting the kind of messy problems that engineers are likely to encounter in their professional 
careers. Furthermore, such interdisciplinary and transdisciplinary approaches and opportunities are recognized as critical for sustainability teaching and learning.

\section{Literature Review}

Transdisciplinarity can be defined as a type of team-based problem-solving approach that acknowledges complexity, social accountability, mutual learning, and the co-creation of knowledge including by all stakeholders. While studies affirm transdisciplinarity as a successful approach to addressing complex, ill-structured, value-laden, and multi-scaled problems [3], the literature emphasizes that, without a team of diverse members each possessing transdisciplinary skills, the team-based approach to large complex problems can result in spectacular failure [4].

In the context of this article, we identified the different disciplines within each project, and organized the student teams accordingly, creating a multidisciplinary background. Later, they structured their work through an interdisciplinary interaction where participants "integrated information, data, techniques, tools, perspectives, concepts, and/or theories from their own disciplines of specialized knowledge to propose a solution to the problems addressed by the sustainability project, whose solutions are always beyond the scope of a single discipline [5]. The stakeholder participation, guidance, and advice should result in a transdisciplinary project when the final presentations lead to a higher understanding of the problems behind the project, which provide insights for future solutions [2].

In contrast to the need for a transdisciplinary discourse in addressing sustainability problems within the urban environment, professional education programs relating to the design, operation, and maintenance of both cities and the industrial activities on which cities depend do not train students in interdisciplinary work. The review presented here starts by describing recent progress in transdisciplinary education within architecture and engineering, and then reviews literature relating to indicators of transdisciplinarity. Finally, it summarizes literature pertaining to three indicators, which we view as critical to the transdisciplinary skills needed when managing complex sustainability problems.

\subsection{Transdisciplinary Education in Architecture and Engineering}

Tejedor et al. [6] describe three discourses within the transdisciplinary education literature, namely "transcendence", "problem-solving", and "transgression", and suggest that trans-disciplinary engineering education experiences reported in the literature exist within the problem-solving discourse. The authors conclude that teaching and learning experiences with the problem-solving discourse tend to cross disciplinary boundaries timidly, while simultaneously embracing extensive stakeholder participation in the problem solving process. Further, they underline literature reports showing that such education experiences can enhance critical thinking.

This role of transdisciplinary education in developing critical thinking skills of engineering students is echoed in the education literature respecting architecture. For example, Olmos-Gómez [5] argues that, in addition to improving the abilities of students to think critically, recognize bias, and tolerate ambiguity, learning in a transdisciplinary environment may also clarify and reinforce disciplinary knowledge. The body of evidence offered in support of his claim includes personal observations and interpretations of student team behaviour in a bio-mimetic design course taken by both biological science and architecture students. Riley et al. [7] make similar claims in reference to an architectural engineering course involving a significant community engagement project, and provide summaries of both student interviews and survey responses, stating "The well-rounded growth that students ... have demonstrated in their survey responses underscore the effectiveness of the ... holistic approach to engineering and architecture education".

Lonngren et al. [8] employ a phenomenographic research approach to gain insights relating to the ability of engineering undergraduate students to address large and complex sustainability problems. The "Integrated and balanced" approach, which this paper describes as one of four used by engineering students, involves viewing such problems as an "integrated whole" consisting of technical challenges 
and also social and ecological challenges, all of which are "interconnected in complex ways". Further, this approach also involves finding ways to balance the needs of different stakeholders while positively affecting all stakeholders. Critically, the authors found that whether or not individual students take this "integrated and balanced" approach to addressing a large and complex sustainability problem depends on the context of their learning. Such findings align with the education literature, where it is established that different cognitive processes are at play in addressing ill-structured problems compared to well-structured problems. Since the education literature reports that practice is required in order to consistently approach a problem appropriately, Lönngren et al. [8] recommend that STEM students engage in multiple opportunities to grapple with ill-structured problems.

\subsection{Indicators of Transdiciplinarity Skills}

Thinking in a complex and interlined manner, demonstrating interpersonal competencies such as open-mindedness and empathy, and the ability to reflect on knowledge integration are personal characteristics of individuals who work well in a transdisciplinary environment. Following from this characterization of transdisciplinarity, Tan et al. [9] use systems thinking, empathy, and metacognition as proxy indicators of the basket of skills which lead to successful transdisciplinary relationships.

Systems thinking is a core competency of sustainability knowledge involving the ability to connect the practical to the theoretical, and one level of a problem with multiple levels of the same problem. In other words, systems thinkers constructed and apply integrative knowledge systems, which is really transdisciplinary when new paradigms are reached [2].

Empathic perspective-taking is relevant to engineers because it leads to understanding and care for the concerns and needs of stakeholders. This, in turn, facilitates ethical decision-making and human-centered design. For these reasons, empathy is increasingly recognized as a core skill in professional education.

Developing metacognition as the foundational process of active learning within engineering programs is proposed by Hess [10]. Indeed, metacognition is well-known to play an important role in high-quality learning by students and influences transdisciplinary interactions by enabling individuals to monitor, reflect on, and adapt learning processes in a multidimensional context.

\section{Workshop Elements and Methodology}

\subsection{Workshop Design}

The students worked in small groups over five days to deliver new concepts for existing challenges, making the most of their talents as individuals and drawing on their respective disciplinary backgrounds.

Each morning, the faculty would take it in turns to provide some stimulation, presenting on aspects of sustainability drawn from their own disciplinary perspective. This covered a wide range of areas from carbon capture and storage, problem framing, integrated design process (at product, process, and building levels), energy systems, creativity, and planning for green infrastructure.

The students would then work on a project in teams of 3-4, mixed by institution and subject to try and give them the best experience of working with contemporaries with different backgrounds and perspectives from themselves. Through the three years, 15 real projects were presented to the students which combined a mix of environmental, social, economic, and technical dimensions. These represented the kind of challenges we wish to prepare engineers for, as they are current, real, an open ended problems with no obvious solutions, reflecting the kind of messy problems they are likely to encounter in their professional careers.

For assessing the interdisciplinary work, both faculty and students were evaluated through different approaches per year. The details of the disciplinary backgrounds of students and faculty participating on the workshops are shown in Tables 1 and 2. Finally, the detail on the number of projects and related disciplines developed by the different teams of students are presented in Table 3 . 
Table 1. Student disciplinary backgrounds for each year.

\begin{tabular}{|c|c|c|c|}
\hline Institution/Year & 2017 & 2018 & 2019 \\
\hline UC Cork & - & 2 Engineers & - \\
\hline Cambridge U. & 4 Sustainability & 2 Sustainability & - \\
\hline UBC & $\begin{array}{l}1 \text { Lawyer } \\
1 \text { Engineer }\end{array}$ & $\begin{array}{l}1 \text { Planner } \\
1 \text { Engineer }\end{array}$ & 1 Engineer \\
\hline Carnegie-Mellon U. & 0 & $\begin{array}{l}3 \text { Architects } \\
3 \text { Engineers }\end{array}$ & 1 Architect \\
\hline TU Delft & 6 Engineers & 2 Engineers & - \\
\hline TU Berlin & - & - & 2 Architects \\
\hline Paris-Saclay & - & . & 1 Chemist \\
\hline Vietnam & - & 5 Environment & - \\
\hline UPV & 4 Engineers & $\begin{array}{l}3 \text { Engineers } \\
10 \text { Architects }\end{array}$ & $\begin{array}{l}1 \text { Engineer } \\
5 \text { Architects }\end{array}$ \\
\hline TOTAL & 18 & 32 & 11 \\
\hline
\end{tabular}

Table 2. Faculty and project disciplines for each year.

\begin{tabular}{cccc}
\hline Institution/Year & $\mathbf{2 0 1 7}$ & $\mathbf{2 0 1 8}$ & $\mathbf{2 0 1 9}$ \\
\hline UC Cork & 1 Engineer & 1 Engineer & 1 Engineer \\
Cambridge U. & 1 Sustainability & 1 Sustainability & 1 Sustainability \\
UBC & 2 Engineers & 2 Engineers & 1 Engineer \\
Carnegie-Mellon U. & - & 1 Architect & 1 Architect \\
TU Delft & 1 Engineer & 1 Economist & 1 Economist \\
TU Berlin & - & - & - \\
Paris-Saclay & - & - & 1 Architect \\
& 1 Engineer & 1 Engineer & 1 Chemist \\
UPV & & 5 Architects & 1 Engineer \\
& 6 & 13 & 11 \\
\hline TOTAL & &
\end{tabular}

Table 3. Projects and related disciplines per year.

\begin{tabular}{ccc}
\hline 2017 & 2018 & 2019 \\
\hline 1 Refurbishment & 2 Refurbishment & \\
1 Environment & 2 Tourism & 1 Energy \\
1 Urbanism & 1 Environment & 1 Tourism \\
& 1 Energy & \\
& 2 Urbanism & \\
\hline 3 & 1 Materials & 2 \\
\hline
\end{tabular}

Besides the technical competence development, the program required a group-work competence development focused on multidisciplinary exchange. Team building was therefore embedded in the week's program for strong social interactions. Through leisure activities, students and faculty could meet and get to know each other as individuals. During the first ISAlab, the workshop was identified as the "bandstand", using a jazz metaphor for a place where musicians improvise their music.

The kick-off was always a session where students and faculty worked together on a joint preparation of a meal, which along with weekly walking tours, social meals, and leisure activities created a very compact and relaxed team environment. This helped break down barriers in the early part of the week, and later developed a space for more reflection, free thinking, and the exchanging of ideas as the projects came to fruition. In Figure 1, all team activities before and during the workshop are summarized, and in Figure 2, the Workshop "bandstand" elements are depicted. 


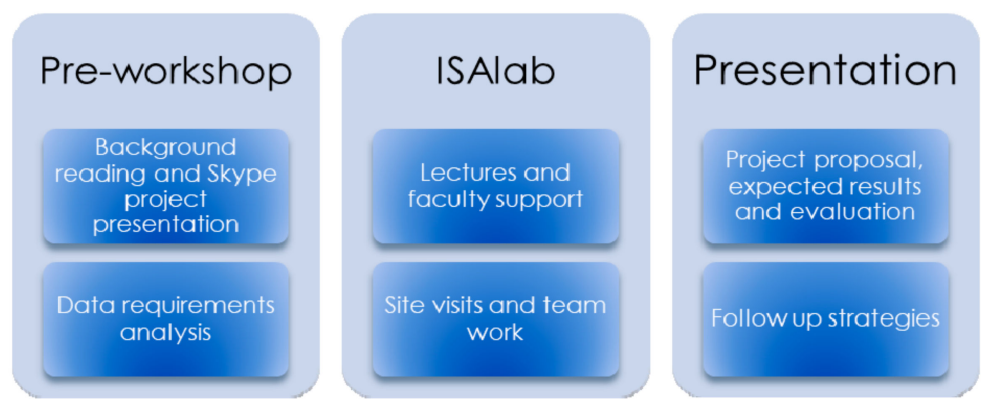

Figure 1. Workshop team interactions.

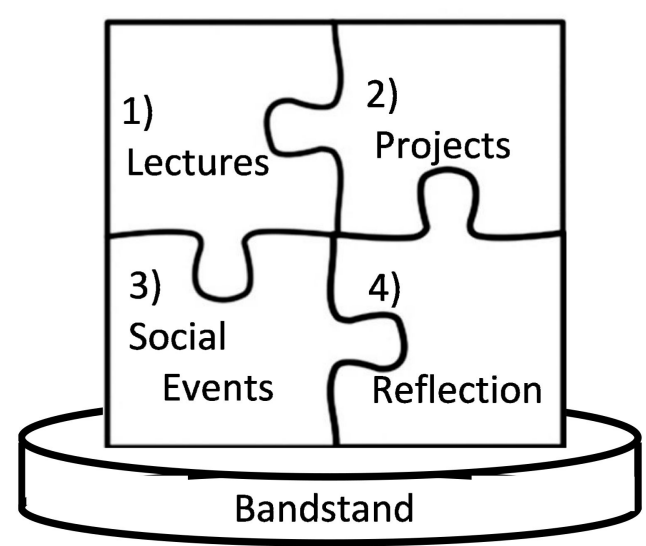

Figure 2. Workshop (bandstand) elements.

This study extends the transdisciplinary education literature into architecture and engineering by exploring surrogate indicators of transdisciplinarity introduced by Tan et al. [9]. Specifically, the following questions guided the study:

- To what extent are transdisciplinary skills generally, and systems thinking, empathic thinking and metacognition in specifically, reinforced and/or developed through ISAlab?

- What workshop elements reinforce and/or support the development of these skills?

- Do transdiscipinary aspects of ISAlab translate into general education principles for teaching and learning systems thinking, empathic thinking, and metacognition?

These research questions were explored by collecting information from both workshop participants (i.e., masters-level students) and facilitators (i.e., faculty members from different universities). We followed the protocol offered by Lönngren et al. [8], namely:

- Systems thinking: Reading/reflecting.

- Systems thinking: Problematization.

- Empathic thinking: Free Solution.

- Empathic thinking: Role Play.

- Reflection on the problem.

This was translated into the ISAlab context, in order to collect data relevant to our stated research questions. Specifically, through focus-group discussions and a survey at the end of the workshop (but before the final presentations), we asked each participant if the program allowed them to:

1. become familiar with contextual issues relating to a development project local to Valencia, and then brainstorm alternative conceptual approaches, via a series of divergent and convergent thought experiments. This question relates to system thinking (reading/reflection category). 
2. explore implications of their initial ideas for addressing development problems. This question relates to system thinking (problematization category from systems thinking).

3. further develop their ideas for addressing development problems, via a series of divergent and convergent thought experiments. This question relates to empathic thinking (the free solution category).

4. prepare and conduct a short and engaging pitch to present their ideas to stakeholders, project supervisors, workshop facilitators, and fellow workshop participants. This question relates to empathic thinking (the role play category).

5. compare and contrast their own project experiences with those of other workshop participants through post-workshop focus group discussions. This answer was obtained by reflecting on the problem.

\subsection{Data Collection from Workshop Participants}

Data relating to workshop experiences of the participants were collected via an informal post-workshop e-survey, undertaken by all students after the workshop, and through focus group discussions during the last day of the workshop. The survey also aimed to determine each student's level of metacognition.

The purpose of the survey (available in reference [9]) was to obtain self-assessment data indicating the levels of systems and empathic thinking that students believe they developed during the workshop (research question (RQ)5 on 3.1).

The survey was followed by focus-group discussions designed under the directives presented by Lönngren et al. [8] for the remaining RQs (see 3.1). The primary purpose of these discussions was to ensure that students left the workshop with general ideas they might apply to address future complex problems they may encounter. In addition, it was expected that evidence in focus group conversations might reveal aspects of the workshop that particularly supported transdisciplinary skill development. Focus-group facilitators were sensitive to indicators of transdisciplinary behaviour displayed during the discussion.

For arranging the focus-groups, participants were divided into groups with 3-5 participants each. Care was taken to ensure that each group included participants from different institutions, and also that each group had representation from different project teams. One workshop facilitator led each focus group discussion. Each discussion lasted approximately 30 to 45 minutes. Questions discussed in each group, which were developed according to the method in reference [11], are presented in Table 4.

Each facilitator asked the four primary questions and each drew-out the discussion with a judicious choice of sub-questions. At the end of the focus-group discussions, the participants voted on their personal evaluation for each discussion point.

The numeric data were obtained at the end of the focus groups by counting the percentual number of votes per category. The focus-groups conversations were recorded for later qualitative analysis on specific answers relevant to the learning experience evolution and for developing a qualitative evaluation of the RQs. 
Table 4. Focus Group Discussion Questions.

RQ 1: Tell us about your experience of the week as a whole

- What were the key issues your teams discussed?

- o what extent were these issues connected?

- What similarities did you see across the projects?

- What differences did you see across the projects?

RQ 2: What was your experience of sustainability during the week/projects?

- What were the key issues your teams discussed?

- To what extent were these issues connected?

- What similarities did you see across the projects?

- What differences did you see across the projects?

RQ 3: What are the key learnings you will take away from the week?

- hat do you think might be helpful for similar future projects?

- What might be useful in your professional lives?

- What activities were most helpful in learning?

RQ 4: Is there anything else you'd like to say about the experience?

- What would you like to say about the experience?

- What worked well?

- What could be improved?

\section{Results}

On the next page, the results obtained from the quantitative analysis pf the five research questions (RQs) are presented. On each figure (Figures 3-7), the responses are shown on a percentual part of the overall bar. Each graph presents data for one of the research questions per year and the corresponding average.

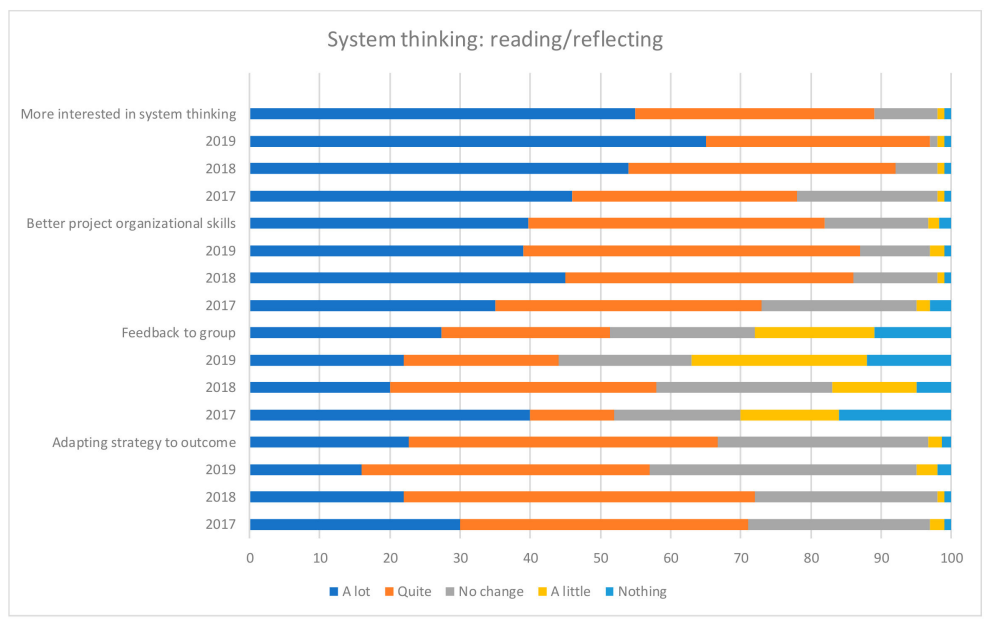

Figure 3. RQ1: Alternative conceptual approaches (Systems thinking: reading/reflecting). 


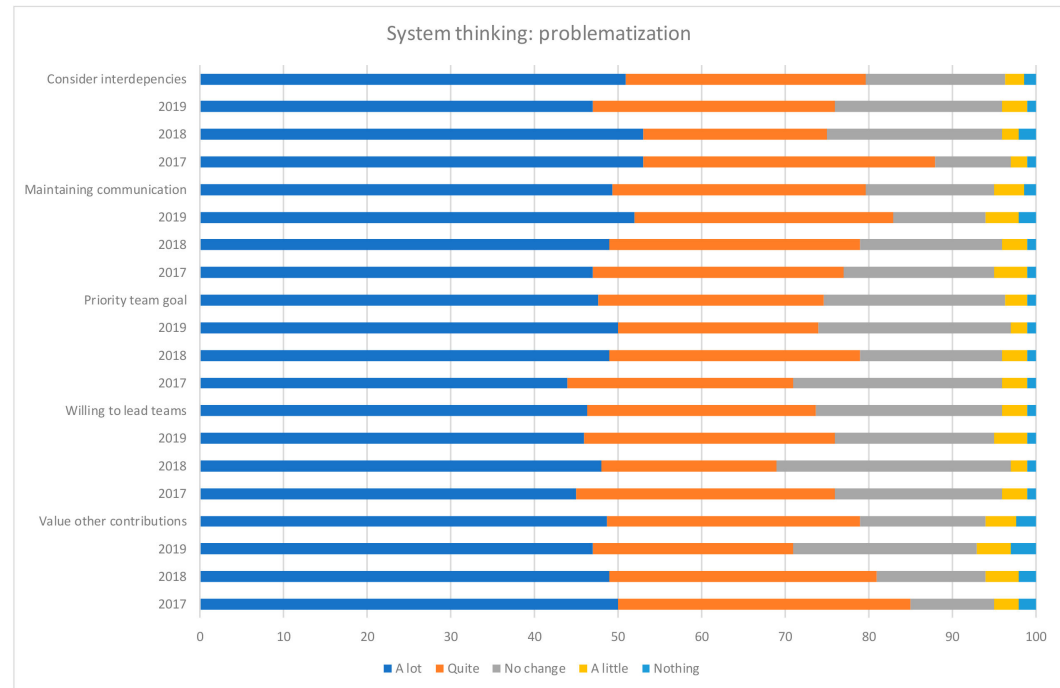

Figure 4. RQ2: Ideas implication in the development problem (Systems thinking: problematization).

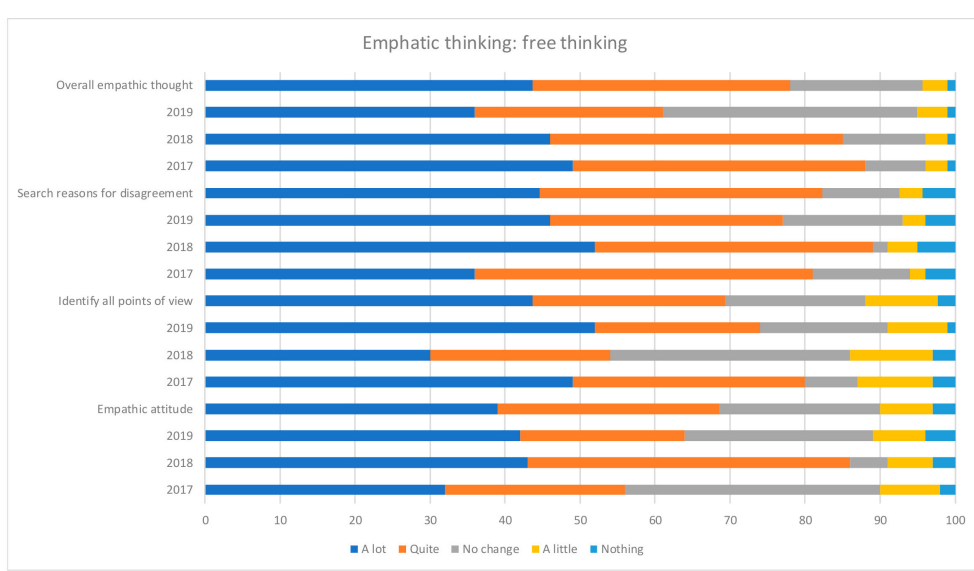

Figure 5. RQ3: Addressing the development problem (Empathic thinking: free solution).

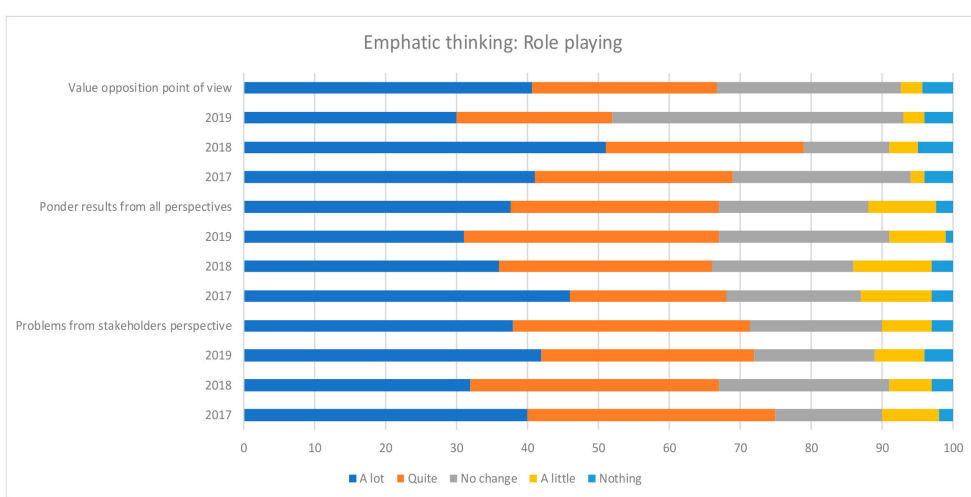

Figure 6. RQ4: Results from pitch exercise (Empathic thinking: Role playing). 


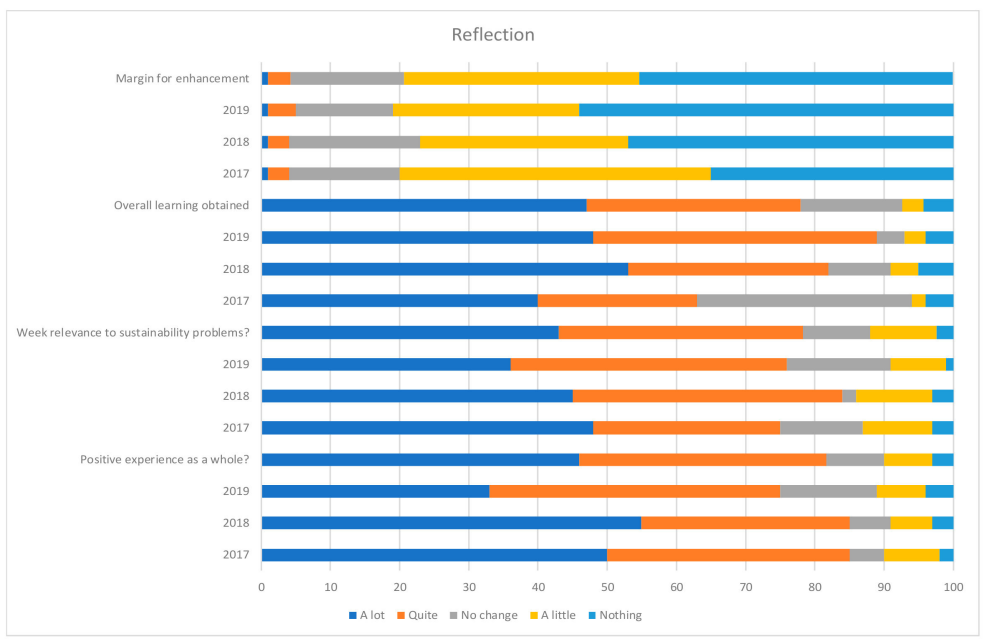

Figure 7. RQ5: Evaluation of workshop experiences (Reflection).

The analysis of the quantitative data through the lens of the focus groups discussion analysis, together with the review of the recordings during the discussions, supports the following qualitative findings on the topics addressed by the workshop design:

- Interdisciplinary findings [12]:

o Many students identified as the most relevant progress area as being able to recognize and articulate the "other side of a coin" in seeing beyond their own discipline.

o Modeling transdisciplinary working relationship between faculty members of different backgrounds and mentors from stakeholders gave students an insight into a higher understanding of the sustainability problems through the confrontation of different perspectives. The knowledge developed encouraged them to be open to differences and hold dialogues.

o One striking characteristic of a transdisciplinary team in action was the absence of a shared disciplinary language, which showed how correctly defining the problems through the stakeholders' different perspectives facilitated simpler approaches to finding the solution.

o A certain emergence of disciplines was observed through examining the project outputs where "integration" of disciplines was shown. In general, students experienced producing deliverables that were not possible independently. This is a clear interdisciplinary result common to all projects and participants.

- Metacognition [13]:

o Many students became aware of delivering contributions to the project despite being outside of their own disciplinary backgrounds. This is a clear example of developing knowledge beyond their initial position and awareness.

o There were levels of self-awareness of individuals in the groups. Many students were able to step back from their experience and ask themselves about their own behaviour and project that self-awareness into the future.

o Students expressed levels of self-reflections on the problems and the strategies used to address the problem. Many students remarked that this was the first time they had worked on a project with people from outside their own training and how amazing it was to recognize the synergies of working with people with different ways of thinking.

o Levels of planning, progress monitoring, evaluation, and adaptation of strategies in problem solving in a few instances were observed. The individual experiences developed into larger scales, recognizing different methods and monitoring progress. 
- $\quad$ Systems thinking [6]:

o The most relevant discussion was on how to transfer knowledge at the community basis (in thinking about indirect and long-term impacts of proposals).

o Many students commented on the impacts of the proposal at different physical and social scales, and over different time scales were considered.

o One of the main comments raised by students was the importance of detailed (e.g., technical) and large-scale systems issues to be considered, as well as their realization of existing connections.

o Some students expressed interconnections not just between financial and nature-based systems, but also between different knowledge domains such as the energy systems for regenerative communities.

- Empathy [14]:

o Perhaps due to the length of the workshop, there was a general coherence to the teams, and a relative lack of conflicts that may have reflected how teams handled disagreement. Thus, little evidence is shown on how conflicts were managed between teams.

o In general, the level of active listening in the group was good, based on positive and very relevant inputs to the discussion groups.

o Empathy was present in the degree to which individuals acknowledged and incorporated different opinions into the discussion.

o Individual behaviour indicated a general openness to novel perspectives of other group members (e.g., speaking/communicating constructively to the organic nature of the discussions). Students were exposed to cross-cultural experiences, and very different disciplinary backgrounds, which allowed relevant project co-creation.

\section{Discussion}

The core of sustainability is the enactment of systems thinking to address complex problems and it is perhaps not surprising that the literature abounds with descriptions of ways in which systems thinking by students may be assessed. During the investigation presented here, student survey results suggest a belief among respondents that their systems thinking was improved by their workshop experiences. However, we did not find significant evidence of systems thinking within the focus group discussions, nor did the faculty observe direct evidence of systems thinking during the time when student teams were working on their projects. It is therefore interesting that the student presentations and associated abstracts held evidence of significant systems thinking.

Perhaps not surprisingly, the interdisciplinary work reported in this paper falls within the "problem-solving" discourse described in reference [11]. The workshop participants were from only two primary disciplines: architecture and engineering, and, while a cross-section of co-lateral disciplines were represented, few shared a pragmatic perspective for addressing problems. Thus, while student teams certainly found significant differences in their knowledge domains and ways of approaching their project, we argue there was a shared sense of problem-solving between students from the different disciplines, thus the disciplinary boundaries in the ISAlab workshop were not as thick as might be imagined if other, more diverse, disciplines had participated. As stated by one faculty member who has thought deeply about involving an array of disciplines in the workshop teams: "we may have had a far greater and interesting challenge if we'd had sociologists and law students and economists with the engineers and architects".

Also in alignment with the observations of reference [11], students in the ISAlab workshop focused on the need for stakeholder participation in decisions making and this focus was shared by at least some faculty members. There seemed to be consensus that stakeholders sometimes thought of the project in different ways to the students, and students thought it was essential that stakeholders be open to the student team's proposal. In some cases, the faculty members thought students may 
have had an empathic attitude toward the stakeholders. " ... one student ... [said] ... it was critical to understand what the stakeholders wanted to achieve, indicating that considerations went into cultivating empathy towards those who are impacted by their solutions". This is a particularly relevant finding which allowed for a real transdisciplinary result in these stakeholder mentored groups due to the enhanced problem definition result obtained in these teams.

\section{Conclusions}

This workshop has developed a new joint approach involving all the participating universities during the design phase of the project. The results have shown the relevance of this experience for developing transdisciplinary skills through cooperative project work.

One of the session introductory pieces, proposed during the initial faculty brainstorming session, involved playing part of a TED talk/performance by jazz artist Stefan Harris, entitled 'There are no mistakes on the bandstand' (Harris, 2011) [14]. This largely self-explanatory piece on the value of jazz improvisation (essentially every 'mistake' is an opportunity in jazz, thus the only mistake is when no one accepts/reacts to a note) seemed to be a useful way to help get the creative juices flowing among the student groups from the start, while also encouraging the establishment of an ethos throughout the workshop which encouraged cohesion, innovation, creativity, and exploration among the students.

Listening, collaborative development, and improvisation were thus explicitly privileged over the course of the workshops, rather than competition and trying to dominate the discussion with the best ideas, by force of personality, or with inflexible plans. That said, the dissenting voice-or the metaphorical bum note, i.e., one which perhaps did not chime with the preceding melody or set of ideas-was also welcomed to challenge the status quo and ensure that groupthink did not take hold.

This seemed to chime very well among the students, and the faculty could increasingly identify with the metaphor too, in particular with the interactive and iterative process of engagement we ourselves experienced both in developing the program session details 'on the hoof', in a way that required the faculty to listen and learn from each other and from our students. While challenging at times, this was ultimately hugely fruitful and rewarding.

As proof of the successful result, during 2020 the first joint projects will be developed by multidisciplinary teams of 3-4 students working together to develop part of the overall projects assigned. In doing so, they will not only progress their Master thesis, but also obtain a very relevant and reach experience reinforcing many skills, which will be very valuable for their future professional careers.

Author Contributions: J.O.-M. coordinated all the ISAlab workshops and developed the analysis together with attending faculty from all Institutions. E.d.1.P.-P. extracted the conclusions from the audio recordings obtained on the focus-groups discussions, and R.C.-M. post-processed the information obtained through the different surveys. All authors have read and agreed to the published version of the manuscript

Funding: This research has been co-funded by the Erasmus+ KA2 program of the European Union under the "SAUNAC" project

Conflicts of Interest: The authors declare no conflicts of interest.

\section{References}

1. Maruna, M. Toward the integration of SDGs in higher planning education: Insights from integrated urbanism study program in Belgrade. Sustainability 2019, 11, 4519. [CrossRef]

2. Pohl, C.; Hirsch Hadorn, G. Principles for Designing Transdisciplinary Research-proposed by the Swiss Academies of Arts and Sciences; Oekom Verlag: München, Germany, 2007; p. 2.

3. Fortuin, K.P.J.; van Koppen, C.S.A. Teaching and learning reflexive skills in inter- and transdisciplinary research: A framework and its application in environmental science education. Environ. Educ. Res. 2016, 22, 697-716. [CrossRef]

4. Balaras, C.A.; Droutsa, K.G.; Dascalaki, E.G.; Kontoyiannidis, S.; Moro, A.; Bazzan, E. Urban sustainability audits and ratings of the built environment. Energies 2019, 12, 4243. [CrossRef] 
5. Olmos-Gómez, M.C.; Estrada-Vidal, L.I.; Ruiz-Garzón, F.; López-Cordero, R.; Mohamed-Mohand, L. Making future teachers more aware of issues related to sustainability: An assessment of best practices. Sustainability 2019, 11, 7222. [CrossRef]

6. Tejedor, G.; Segalàs, J.; Rosas-Casals, M. Transdisciplinarity in higher education for sustainability: How discourses are approached in engineering education. J. Clean. Prod. 2018, 175, 29-37. [CrossRef]

7. Riley, D.R.; Thatcher, C.E.; Workman, E.A. Developing and applying green building technology in an indigenous community: An engaged approach to sustainability education. Int. J. Sustain. High. Educ. 2006, 7, 142-157. [CrossRef]

8. Lönngren, J.; Svanström, M. Systems thinking for dealing with wicked sustainability problems: Beyond functionalist approaches. In New Developments in Engineering Education for Sustainable Development; World Sustainability, Series; Leal Filho, W., Nesbit, S., Eds.; Springer: Cham, Germany, 2016; pp. 151-160.

9. Tan, T.; Nesbit, S.; Ellis, N.; Ostafichuk, P. Crossing boundaries: Developing transdisciplinary skills in engineering education. In Proceedings of the Canadian Engineering Education Association (CEEA) Conference, Vancouver, BC, Canada, 3-6 June 2018; Volume 107, pp. 1-18.

10. Hess, D.W.; Strand, C.; Strand, N. Teaching ethics in investment classes: A series of vignettes. J. Financ. Educ. 2004, 30, 41-60.

11. NAS/NAE/IOM. Facilitating Interdisciplinary Research; National Academy of Sciences: Washington, DC, USA; National Academy of Engineering: Washington, DC, USA; Institute of Medicine: Washington, DC, USA; The National Academies Press: Washington, DC, USA, 2005; Volume 306, p. 188.

12. Akamatsu, D.; Nakaya, M.; Koizumi, R. Effects of metacognitive strategies on the self-regulated learning process: The mediating effects of self-efficacy. Behav. Sci. 2019, 9, 128. [CrossRef]

13. Aleksić, A.; Načinović Braje, I.; Rašić Jelavić, S. Creating sustainable work environments by developing cultures that diminish deviance. Sustainability 2019, 11, 7031. [CrossRef]

14. Stefon, H. There are no mistakes on the bandstand. Available online: https://archive.org/details/StefonHarris_ 2011S (accessed on 24 January 2020).

(C) 2020 by the authors. Licensee MDPI, Basel, Switzerland. This article is an open access article distributed under the terms and conditions of the Creative Commons Attribution (CC BY) license (http://creativecommons.org/licenses/by/4.0/). 